Research Article

\title{
A Decision Model Assessing the Owner and Contractor's Conflict Behaviors in Construction Projects
}

\author{
Guangdong Wu $\mathbb{D}^{1},{ }^{1}$ Huanming Wang $\mathbb{D}^{2}{ }^{2}$ and Ruidong Chang ${ }^{3}$ \\ ${ }^{1}$ Department of Construction Management, Jiangxi University of Finance and Economics, Nanchang 330013, China \\ ${ }^{2}$ Faculty of Humanities and Social Sciences, Dalian University of Technology, Dalian 116024, China \\ ${ }^{3}$ Centre for Comparative Construction Research, Faculty of Society and Design, Bond University, Gold Coast, \\ QLD 4226, Australia
}

Correspondence should be addressed to Huanming Wang; whm715@dlut.edu.cn

Received 2 January 2018; Accepted 25 February 2018; Published 14 May 2018

Academic Editor: Yingbin Feng

Copyright (c) 2018 Guangdong Wu et al. This is an open access article distributed under the Creative Commons Attribution License, which permits unrestricted use, distribution, and reproduction in any medium, provided the original work is properly cited.

\begin{abstract}
Considering the effects of the contractor's conflict behaviors on the project benefit, a decision model between the owner and contractor's conflict behaviors in construction projects was constructed using the principal-agent theory and game theory. The model was analyzed under nonconflicting and conflicting conditions, and a numerical simulation and example analysis were proposed to verify the constructed model's conclusion. The results showed that the effort levels of the owner and contractor not only relate to benefit-sharing coefficient and effort outcome coefficient but also depend on the contractor's ability of converting the conflict into benefit and the loss caused by conflict behaviors. A higher ability of converting conflicts into benefits and lower levels of the loss caused by conflict behaviors for the contractor lead to lower levels of the net benefit of the owner, conversely higher levels of the net benefit of the contractor. Balancing the contractor's ability of converting conflicts into benefits and the loss caused by conflict behaviors lead to a more reasonable risk allocation between the owner and contractor, improving the effort level and net benefit. To add value to the construction project, the owner should establish an impartial and reasonable benefit-sharing mechanism, optimize the owner and contractor's resource arrangement, maximize the positive effect of conflict on project benefits, and avoid the negative effect of conflict. Few studies to date have investigated the effects of conflict behaviors on project benefits in terms of modeling and simulation in construction projects. As such, this study bridges this gap and contributes significant theoretical and practical insights about managing conflict behaviors in an interorganizational context, thus enhancing performance in construction projects.
\end{abstract}

\section{Introduction}

A typical construction project involves numerous projectbased organizations, including the owner, the contractor, the subcontractor, the designer, and the consultant [1]. This creates a complex adaptive system with common objectives. The resources exchange and knowledge transfers occur between different participants during the project implementation. The heterogeneity of diverse participants inevitably leads to project conflicts. Losses caused by conflicts with untimely and inappropriate solutions account for approximately $3-5 \%$ of the total project investment [2]. Project conflicts involving project-based organizations occur along with the project life cycle occur from the initial stage to the operational stage. Because of these conflicts, project-based organizations experience an increasingly negative relationship, particularly between the owner and the contractor [3]. These adversarial behaviors include disparities between the owner and contractor, the objective conflict between the owner and contractor, and contention about resources based on different objectives. These behaviors consistently lead to disputes and negotiations between the owner and contractor, making it difficult to achieve an ideal cooperative effect [4]. Furthermore, these adversarial behaviors consistently lead to time and cost overruns, and complicate achievement of project objectives [5]. A critical factor for these behaviors is the absence of a conflict management mechanism, especially between the owner and contractor. 
Therefore, more attention should be paid to investigate the occurrence of conflicts and mechanisms for managing it.

Managing construction projects inevitably involves contracts between the owner and contractor. Contracts are usually incomplete due to the inherent nature of construction projects; these projects have complex and uncertain transactions and processes, result in single products, and are unique-they only happen once [6]. These contracts significantly impact project success, particularly on projects involving more complex construction technologies and more specific divisions of work. All the efforts of project-based organizations are centered on project performance; inconsistencies in objectives, knowledge, and benefits lead to conflicts, thereby negatively impacting performance $[7,8]$. Project participants are interdependent of each other, consistently leading to conflicts due to the diversity of knowledge and benefits [9]. Furthermore, the different core capabilities, information asymmetry, and unclear rights and responsibilities between participants also lead to conflicts [10].

This study constructed a decision model using game theory to examine conflict behaviors between the owner and contractor. In this model, the contractor is assumed to trigger the conflict behavior. The owner receives and responses to the conflict behavior. Therefore, the model can be used to assess: (i) under what conditions the contractor will trigger the conflict behavior; (ii) under what conditions the contractor can obtain a benefit from the conflict behavior; and (iii) how the owner can guard against the loss caused by the conflict behavior. Previous studies focused on the factors influencing conflicts and their effects on performance using empirical data. Few studies, however, have investigated the internal mechanism in terms of modeling and simulations in construction projects. This study bridges this gap and contributes significant theoretical and practical insights about conflicts occurring in an interorganizational context. These insights can enhance management performance in construction projects.

\section{Literature Review}

Conflict is a phenomenon that occurs when there are different beliefs, thoughts, and benefits between two or more individuals and is a complicated social and psychological phenomenon involving different levels and dimensions [11]. These different types and levels of conflict can interact and be interdependent [12]. Recently, researchers have introduced conflict theory to the field of construction project management. This study area has emerged because of the interdependencies and diversity between participants and imperfect management mechanisms, which may cause conflicts in construction projects [13].

The traditional definition of conflict emphasizes the opposition of objectives within a competitive background, and proposes that conflict originates from the opposite relationships with respect to benefits. Resource scarcity and the divergence of objectives are baseline factors assumed by this definition. The main result is that one party achieves its own objectives at the cost of other party's benefit. Conflict behaviors between an owner and contractor, the research object for this study, reflect a type of interorganizational conflict, namely, the conflict behavior between stakeholders in construction projects. Sources of conflicts in construction projects include limited public resources, different understandings of the project plan, and different task priorities $[14,15]$. Additionally, the industrial characteristics of the building industry create sources of conflicts, including the discreteness of the construction link, low efficiencies, and cost overruns [16]. Therefore, conflict in construction projects is an interaction between different participants with different perceptions and viewpoints on a process or task. Conflict results from participant-related factors, project-related factors, and issues related to communication, benefit allocation, and trust. The background of projects provided a suitable environment to analyze conflict, because conflicts in construction projects are behaviorally related, and significantly affect performance.

Conflict can have constructive and destructive effects on performance. In construction projects, the traditional view of conflict is that it causes destructive effects. Xue et al. [17] proposed that performance is an interactive result of collaboration between multiple parties; because conflicts hinder collaboration, they are detrimental to performance. Conflicts can strain the owner and contractor relationship, impeding effective communication, and resulting in cost and time overruns, and low quality and satisfaction $[18,19]$. However, the specific tasks of the project were unconventional. Conflicts can provide different views and knowledge with which to address tasks, improving decision quality [20, 21].

The effects of conflicts on performance may relate to management strategies; different strategies have different results [22]. Chen [23] explored the positive and negative effects in project value creation and found that the total life cycle adjusted the task conflict and project value. Anderson and Polkinghorn [24] discussed the importance of the conflict resolution skills and methods in constructing the Woodrow Wilson bridge; they concluded that process conflict had the greatest influence on performance. Brockman [25] surveyed 74 participants in different construction projects; $56 \%$ of respondents proposed that relationship conflict had destructive effects on performance. Puck and Pregernig [26] conducted a long-term survey of 92 construction teams, arguing that different types of task conflicts had different effects on performance. Chen et al. [3] concluded that conflicts between the owner and contractor were represented by an inverted $U$ shape on cost performance; only moderate degrees of conflict could improve performance. Chen et al. [27] proposed that emotional conflicts effectively mediated decisions and philanthropic paternalism, using empirical data from 108 top managers. Wu [28] found that process and relationship conflicts were negatively related to project success, and task conflict contributed to project success. Therefore, there is still equivocal how conflicts affect performance in construction projects; for example, there is inadequate information about the internal interaction mechanism of conflict. Researchers have validated the constructive and destructive effects on performance using empirical data; however, the interaction mechanism still needs to be discovered and 
analyzed. Modeling and simulation methods are effective tools to uncover the internal mechanism, due to the inherent nature of construction projects.

This study assumed that the contractor is the triggering party and can trigger conflicts through claims and project changes [29]. The owner directly bears the consequence of conflicts, while conflict behaviors can be restrained through reward and penalty mechanism signed in contracts [30]. The contractor experiences two consequences of conflict behavior: gain or lose. Therefore, this study constructed a decision model using game theory to analyze the internal mechanisms of conflict behaviors on performance. The model analysis and conclusions can clarify the effect of conflict on performance, and contribute to the development of effective conflict management strategies. This study contributes significant theoretical and practical insights to the existing body of knowledge on conflict management. This study provides a useful reference for project managers maximize the advantages of the positive effects of conflicts, and avoid the negative effects of conflicts.

\section{Model Description and Solution}

3.1. Model Description. Assume there are two equal projectbased organizations: the owner and the contractor. These organizations cooperate with each other to achieve the successful delivery during project implementation. Conflicts between the owner and contractor consistently occur due to the temporary and dynamic nature of cooperation. This study does not consider the time value of money and proposes the following hypotheses:

(i) The owner is risk-neutral and the contractor is riskaverse. The effort levels of the contractor and owner are $e_{1}$ and $e_{2}$, respectively. The functions of the cost of effort for the contractor and owner are expressed as follows:

$$
C\left(e_{i}\right)=\frac{1}{2} e_{i}^{2} \quad(i=1,2) .
$$

In this study, the parameter $e_{i}$ is not limited to $e_{i}>0$, which means the effort levels of the contractor and owner can be less than zero. If this occurs, the cooperation between the contractor and owner is negative, with neither being willing to allocate resources. The coefficients of the cost of effort for the contractor and the owner are the same and are assigned as one. Generally, the coefficients of the cost of effort are not the same and can be other values. This study focuses on the effects of conflicts on performance; as such, the influences of the coefficients of the cost of effort are not included.

(ii) Assume the contractor and owner can balance their effort level. The project outcome function can be written as [31]

$$
R\left(e_{1}, e_{2}\right)=\kappa_{1} e_{1}+\kappa_{2} e_{2}+\varepsilon .
$$

In this expression, the parameters of $\kappa_{1}>0$ and $\kappa_{2}>0$ are the outcome coefficients of effort levels of the contractor and owner. The coefficients reflect their integrated technology and management level. This is manifested by the ability to transfer input resources to outcomes and is related to staff quality, operational level, and technological ability [32]. The contractor and owner cannot directly observe each other's effort level; the levels can be evaluated based on the input resources and the achievement of objectives. The parameters $e_{1}, e_{2}$, and $\varepsilon$ are mutually independent. The parameter $\varepsilon$ is normally distributed as $N\left(0, \sigma^{2}\right)$, reflecting the influence of the external uncertainty on the outcome function.

(iii) Assume the owner provides a linear incentive contract for the contractor, written as $S=\Omega+$ $\beta R\left(e_{1}, e_{2}\right)$. In this equation, the parameter $\Omega$ is a fixed reward the owner provides the contractor. This reward is a constant and cannot stimulate the contractor to adopt a higher level of effort. Thus, the value can be assigned to zero [33]. The parameter $\beta$ is a coefficient of the project outcome sharing and is within the range $0 \leq \beta \leq 1$. This range reflects the incentive degree of the owner [34]. Additionally, this study focuses on conflict behaviors between the owner and contractor. This is a type of cooperative conflict because the owner and contractor cooperate to achieve successful project delivery, while also maximizing their own benefits. In this situation, inconsistent objectives may lead to conflict behaviors. This study focuses on conflict behaviors during the construction stage, when the contractor has superior information and can trigger conflicts through project changes and claims. Thus, the contractor is the party that can trigger conflicts. In contrast, the owner can only respond to the conflict based on the conflict type and the results.

(iv) When the contractor adopts conflict behaviors, the contractor benefits in two ways. One is the contractual coefficient of benefit sharing $(\beta)$ and the other is the benefit converted through the conflict. Assuming the benefit converted through the conflict depends on the effort levels of the contractor $\left(e_{1}\right)$ and the owner $\left(e_{2}\right)$ and the coefficient $(\mu)$ of converting conflicts to benefits for the contractor $(0<\mu<1)$. Therefore, the benefits converted through the conflict can be presented as $\mu e_{1} e_{2}$, which are paid by the owner. The coefficient of converting conflicts to benefits for the contractor $(\mu)$ reflects the bargaining ability of the contractor who is adopting conflict behaviors. The coefficient relates to the qualification, similar project experiences, and reputation. Additionally, the owner can adjust the level of effort to affect the benefits converted through the conflict. Generally, high values for the coefficient of converting conflicts to benefits and efforts of the contractor lead to lower levels of effort for the owner, even a negative value of the effort level.

Furthermore, when the contractor adopts conflict behaviors, the owner must spend time to address the conflict and prevent the loss. This may lead to the owner distrusting the contractor. Under this condition, adopting conflict behaviors may lead to both current and future losses for the 
contractor. Current losses include failures of project changes and claims and accelerated costs due to an extended conflict resolution period. Future losses include losing opportunities for future cooperation, and a lower reputation due to an unsuitable conflict environment. Assume the coefficient of loss caused by conflict behaviors is $\eta$ and satisfies the condition of $0<\eta<1$. The loss caused by conflict behaviors is $\eta e_{1}$; this variable relates to the effort level, input resources, and cooperative attitude of the contractor. This reflects the fact that higher levels of effort lead to higher levels of loss for the contractor adopting conflicts. The contractor may trigger conflict behaviors when $\mu e_{1} e_{2}>\eta e_{1}$. In other words, the contractor triggers conflict behaviors only when the contractor estimates the benefits exceed the loss brought by the conflicts.

Therefore, when there are conflict behaviors between the owner and contractor, the function of net benefits of the contractor can be expressed as

$$
U_{1}=\beta\left(\kappa_{1} e_{1}+\kappa_{2} e_{2}\right)-\frac{1}{2} e_{1}^{2}+\mu e_{1} e_{2}-\eta e_{1}-\frac{1}{2} \rho \beta^{2} \sigma^{2} .
$$

The function of net benefits of the owner can be written as

$$
U_{2}=(1-\beta)\left(\kappa_{1} e_{1}+\kappa_{2} e_{2}\right)-\frac{1}{2} e_{2}^{2}-\mu e_{1} e_{2}+\eta e_{1} .
$$

The function of project outcome can be written as

$$
U=\kappa_{1} e_{1}+\kappa_{2} e_{2}-\frac{1}{2} e_{1}^{2}-\frac{1}{2} e_{2}^{2}-\frac{1}{2} \rho \beta^{2} \sigma^{2} .
$$

\subsection{Model Solution}

3.2.1. Solution under Nonconflicting Behavior Condition. To compare the effects of conflict behaviors on performance, the proposed model first considered nonconflicting behaviors. Under this condition, the function of net benefits of the contractor and the owner and the function of project outcome can be written as

$$
\begin{aligned}
& U_{1}=\beta\left(\kappa_{1} e_{1}+\kappa_{2} e_{2}\right)-\frac{1}{2} e_{1}^{2}-\frac{1}{2} \rho \beta^{2} \sigma^{2}, \\
& U_{2}=(1-\beta)\left(\kappa_{1} e_{1}+\kappa_{2} e_{2}\right)-\frac{1}{2} e_{2}^{2}, \\
& U=\kappa_{1} e_{1}+\kappa_{2} e_{2}-\frac{1}{2} e_{1}^{2}-\frac{1}{2} e_{2}^{2}-\frac{1}{2} \rho \beta^{2} \sigma^{2} .
\end{aligned}
$$

The first partial derivatives of $e_{1}$ and $e_{2}$ were calculated, and the values were set to zero. This led to the following equation:

$$
\begin{aligned}
& \frac{\partial U_{1}}{\partial e_{1}}=\beta \kappa_{1}-e_{1}=0, \\
& \frac{\partial U_{2}}{\partial e_{2}}=(1-\beta) \kappa_{2}-e_{2}=0 .
\end{aligned}
$$

We solve the above simultaneous equation for $e_{1}$ and $e_{2}$ as follows:

$$
\begin{aligned}
& e_{1}^{* *}=\beta \kappa_{1}, \\
& e_{2}^{* *}=(1-\beta) \kappa_{2} .
\end{aligned}
$$

According to the extremum attributes of functions, the second partial derivatives of $U$ is $\partial^{2} U / \partial \beta^{2}=-\kappa_{1}^{2}-\kappa_{2}^{2}-\rho \sigma^{2}<0$. Substituting (10) into (8), we calculated the partial derivatives of $\beta$. The value was then set to zero and solved as

$$
\beta^{* *}=\frac{\kappa_{1}^{2}}{\kappa_{1}^{2}+\kappa_{2}^{2}+\rho \sigma^{2}} .
$$

3.2.2. Solution under Conflicting Behavior Condition. For (3) and (4), the first partial derivatives of $e_{1}$ and $e_{2}$ were calculated, respectively. The values were then set to zero, and the following equation was obtained:

$$
\begin{aligned}
& \frac{\partial U_{1}}{\partial e_{1}}=\beta \kappa_{1}-e_{1}+\mu e_{2}-\eta=0, \\
& \frac{\partial U_{2}}{\partial e_{2}}=(1-\beta) \kappa_{2}-e_{2}-\mu e_{1}=0 .
\end{aligned}
$$

To solve the above simultaneous equation for $e_{1}$ and $e_{2}$, we obtain

$$
\begin{aligned}
& e_{1}^{*}=\frac{\left(\kappa_{1} \beta-\eta\right)+\mu \kappa_{2}(1-\beta)}{1+\mu^{2}}, \\
& e_{2}^{*}=\frac{\kappa_{2}(1-\beta)-\mu\left(\kappa_{1} \beta-\eta\right)}{1+\mu^{2}} .
\end{aligned}
$$

According to the extremum attributes of functions, the second partial derivatives of $U$ was $\partial^{2} U / \partial \beta^{2}=-\left(\left(\kappa_{1}^{2}+\kappa_{2}^{2}\right) /\right.$ $\left.\left(1+\mu^{2}\right)\right)-\rho \sigma^{2}<0$. The partial derivatives of $\beta$ were calculated by substituting (13) into (5). The value was then set to zero and solved as

$$
\beta^{*}=\frac{\kappa_{1}^{2}+2 \mu \kappa_{1} \kappa_{2}-\eta \kappa_{1}}{\kappa_{1}^{2}+\kappa_{2}^{2}+\rho\left(1+\mu^{2}\right) \sigma^{2}} .
$$

\section{Model Analysis and Simulations}

\subsection{Model Analysis}

Proposition 1. Under the condition of nonconflicting behaviors, the effort levels of the contractor and the owner do not relate to one another. Instead, they are related to their own outcome coefficients of effort levels and the contractual coefficient of benefit sharing. For the contractor, a high level of benefit sharing provided by the owner and a high outcome coefficient contribute to a high effort level. When the project benefit is fixed, a high level of benefit sharing leads to a low benefit for the owner. This leads to a low effort level by the owner. Therefore, when designing the incentive mechanism for the project operation, the owner needs to determine a reasonable coefficient of benefit sharing for the owner, based on the outcome coefficient and contractor effort. In this situation, if the owner adopts an optimal incentive method for the contractor, the specific project can achieve a stable and balanced 
state. It is relatively easy to design an incentive mechanism under the condition of nonconflicting behaviors.

Proof. One has

$$
\begin{aligned}
\frac{\partial e_{1}}{\partial \beta} & =\kappa_{1}>0, \\
\frac{\partial e_{2}}{\partial \beta} & =-\kappa_{2}<0, \\
\frac{\partial e_{2}}{\partial(1-\beta)} & =\kappa_{2}>0 .
\end{aligned}
$$

Proposition 2. Under conditions with conflicting behaviors, the effort levels of the contractor and the owner are related to each other. Effort levels are also related to their own outcome coefficients of effort levels, and the contractual coefficient of benefit sharing (Figure 1). For the contractor, a high level of effort by the owner can motivate the contractor to also adopt a high level of effort. For the owner, a high level of effort by the contractor tends to decrease the owner's enthusiasm to adopt a high level of effort. Because of the coefficients of benefit sharing, and the ability for conflicts to be converted to benefits, the owner needs to provide a higher level of benefit sharing to motivate the contractor to adopt higher levels of effort. A high level of effort by the contractor, combined with a greater ability to convert conflicts to benefits, will lead to more benefits for the contractor. This increases the benefits for the contractor, but damages owner benefits, leading to a lower level of effort for the owner. Additionally, because of the coefficient of loss caused by conflicts, the contractor will balance benefit and loss when triggering conflicts. This leads the contractor to decide to adopt a high or low level of effort. As with the condition of nonconflicting behaviors, a high level of benefit sharing contributes to a high level of effort by the contractor, while leading to a lower level of effort by the owner.

Proof. One has

$$
\begin{aligned}
& e_{1}=\mu e_{2}+\beta \kappa_{1}-\eta \quad \frac{\partial e_{1}}{\partial \beta}=\frac{\kappa_{1}-\mu \kappa_{2}}{1+\mu^{2}}>0 \\
& e_{2}=-\mu e_{1}+(1-\beta) \kappa_{2} \quad \frac{\partial e_{2}}{\partial \beta}=-\frac{\kappa_{2}+\mu \kappa_{1}}{1+\mu^{2}}<0 .
\end{aligned}
$$

Proposition 3. Under the condition of conflicting behaviors, the contractor determines the effort level, by considering the benefit and loss caused by conflict behaviors. Generally, more losses caused by conflicts lead to lower levels of effort by the contractor. For the contractor, the benefits of converting conflicts relate to the owner's effort level; as such, the contractor will examine and weigh the ability of the benefit achieved by convert conflict behaviors to benefits. This determines the reasonable effort level. For the owner, a greater ability to convert conflicts for the benefit of the contractor and lower losses caused by conflicts lead to lower levels of effort by the owner. This reflects the fact that conflict behaviors have constructive or destructive effects on the benefits for the owner and contractor. Whether the contractor chooses to trigger conflicts or not depends on the absolute values of constructive or destructive effects. If triggering conflicts bring benefits to the contractor, the contractor will adopt conflict behaviors. If triggering conflicts cause losses to the contractor, the contractor will not adopt conflict behaviors. This prompts the owner to adopt effective bonus and penalty methods to decrease the loss caused by conflicts. The owner should observe information about effort levels, resource allocations, and benefit sharing by the contractor, and subsequently formulate an effective bonus and penalty mechanism.

Proof. One has

$$
\begin{array}{ll}
\frac{\partial e_{1}^{*}}{\partial \mu}=\frac{\left(1-\mu^{2}\right) \kappa_{2}(1-\beta)-2 \mu\left(\kappa_{1} \beta-\eta\right)}{\left(1+\mu^{2}\right)^{2}}>0 & \frac{\partial e_{1}^{*}}{\partial \eta}=-\frac{1}{1+\mu^{2}}<0 \\
\frac{\partial e_{2}^{*}}{\partial \mu}=-\frac{\left(1-\mu^{2}\right)\left(\kappa_{1} \beta-\eta\right)+2 \mu \kappa_{2}(1-\beta)}{\left(1+\mu^{2}\right)^{2}}<0 & \frac{\partial e_{2}^{*}}{\partial \eta}=\frac{1}{1+\mu^{2}}>0 .
\end{array}
$$

Proposition 4. Under the condition of conflicting behaviors, the coefficient of benefit sharing depends on the outcome ability of the owner and contractor and also depends on the coefficients of converting conflict behaviors to benefits and the loss caused by conflicts. Higher levels of converting conflict behaviors to benefits and lower losses caused by conflicts lead to a higher level of benefit sharing for the owner. This lowers the possibility that the contractor will adopt conflict behaviors. One potential explanation is that conflicts can not only benefit the owner but also simultaneously cause losses to the owner. If the contractor has a greater ability to convert conflicts to benefits, there are more losses for the owner. Thus, if the owner tends to avoid the loss caused by conflicts, the owner will strengthen contractor incentives. Additionally, when the contractor experiences higher losses caused by conflicts, there are more benefits converted from the conflict for the owner. If the owner's benefits can be forecasted, the owner will decrease contractor incentives to enhance its own benefits. 


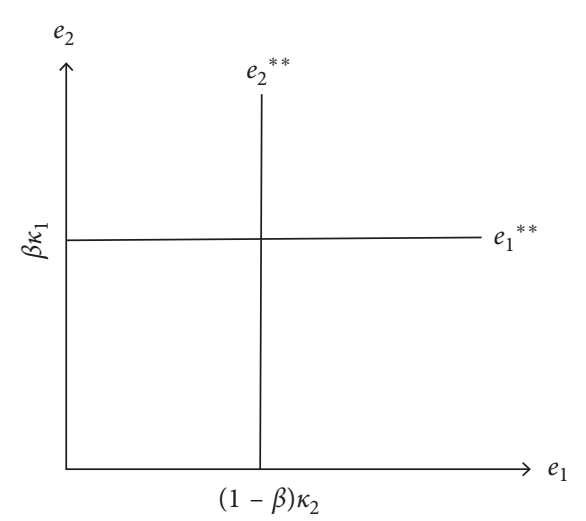

(a)

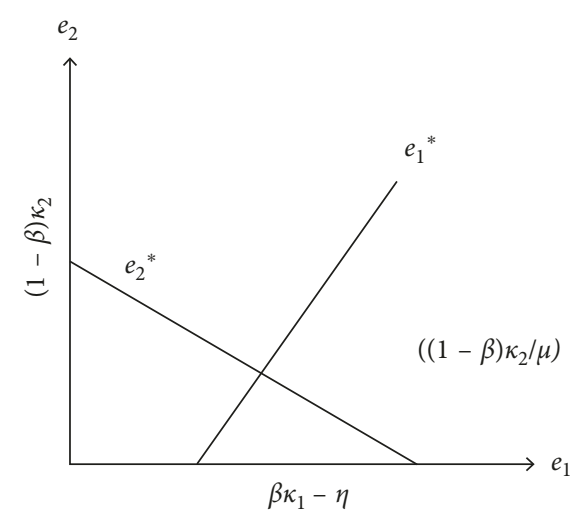

(b)

Figure 1: The effort levels of the owner and contractor under different conditions.

Proof. One has

$$
\begin{aligned}
& \frac{\partial \beta^{*}}{\partial \eta}=-\frac{\kappa_{1}}{\kappa_{1}^{2}+\kappa_{2}^{2}+\rho\left(1+\mu^{2}\right) \sigma^{2}}<0 \\
& \frac{\partial \beta^{*}}{\partial \mu}=\frac{2 \kappa_{1} \kappa_{2}\left[\kappa_{1}^{2}+\kappa_{2}^{2}+\rho\left(1+\mu^{2}\right) \sigma^{2}\right]-2 \mu\left[\kappa_{1}^{2}+2 \mu \kappa_{1} \kappa_{2}-\eta \kappa_{1}\right]}{\left[\kappa_{1}^{2}+\kappa_{2}^{2}+\rho\left(1+\mu^{2}\right) \sigma^{2}\right]^{2}}>\frac{2\left(\kappa_{1} \kappa_{2}-\mu\right)\left[\kappa_{1}^{2}+2 \mu \kappa_{1} \kappa_{2}-\eta \kappa_{1}\right]}{\left[\kappa_{1}^{2}+\kappa_{2}^{2}+\rho\left(1+\mu^{2}\right) \sigma^{2}\right]^{2}}>0 .
\end{aligned}
$$

Proposition 5. When a contractor triggers conflict, that conflict may not bring a greater benefit. This depends on the contractor's own characteristics, such as the outcome coefficient of effort, the ability to convert conflicts to benefits, and the effort level. It also depends on the effort level of the owner. The contractor triggering conflicts brings a better benefit only when $\eta<2 \mu \kappa_{2}$. This indicates that the benefit from converting the conflicts is greater than the loss caused by the conflict. Under this situation, the contractor will trigger conflicts; otherwise, the contractor will not trigger conflicts. Thus, the contractor may enhance its own benefit by triggering conflicts. Consequently, the owner may increase its own benefit by adopting reasonable conflict management strategies. Therefore, if the owner can select reasonable conflict management strategies, it may create a better project benefit. This validates the hypothesis that conflicts may have a positive effect on project benefits.

Proof. One has

$$
\beta^{* *}-\beta^{*}=\frac{\kappa_{1}^{2}}{\kappa_{1}^{2}+\kappa_{2}^{2}+\rho \sigma^{2}}-\frac{\kappa_{1}^{2}+2 \mu \kappa_{1} \kappa_{2}-\eta \kappa_{1}}{\kappa_{1}^{2}+\kappa_{2}^{2}+\rho\left(1+\mu^{2}\right) \sigma^{2}}>\frac{\kappa_{1} \eta-2 \mu \kappa_{1} \kappa_{2}}{\kappa_{1}^{2}+\kappa_{2}^{2}+\rho\left(1+\mu^{2}\right) \sigma^{2}} .
$$

\subsection{Model Simulations}

4.2.1. Effects of Effort Levels of the Owner and Contractor on Project Benefits. Based on (3)-(5), (13), and (14), we set $\kappa_{1}=5, \kappa_{2}=4, \rho \sigma^{2}=20, \mu=0.6$, and $\eta=0.3$. We then simulate the effects of effort levels $\left(e_{1}, e_{2}\right)$ on the project benefit $(U)$, the contractor's net benefit $\left(U_{1}\right)$, and the owner's net benefit $\left(U_{2}\right)$. Figure 2 shows the results. Figure 2(a) shows that project benefits reach an optimal value only when the effort levels of the contractor and owner $\left(e_{1}^{*}, e_{2}^{*}\right)$ achieve a stable and balanced state. This is consistent with the model analysis. Figures 2(b) and 2(c) show that the net benefits of the owner and contractor increase as the other parties' effort level is enhanced; the outcome of enhancing their own effort levels is represented by an inverted $U$ curve. This reflects the fact that the contractor will decide whether to trigger conflicts, based on the owner's effort level. The owner will adjust its own strategy, based on the contractor's behavior. Thus, the effort levels of the contractor and owner affect each other, as well as their own net benefits. Additionally, for the owner and contractor, adjusting their own effort levels is critical to enhancing their own net benefits. However, increasing their own effort levels does not necessarily enhance their own net benefits. This depends on the other parties' effort level. Thus, the owner's optimal strategy is adjusting its strategy based on the contractor's behaviors.

4.2.2. Effects of Coefficients of Converting Conflicts to Benefits and the Loss Caused by Conflicts on Effort Levels. Based on (10), (11), (13), and (14), we set $\kappa_{1}=5, \kappa_{2}=4$, and $\rho \sigma^{2}=20$. We then simulate effects of coefficients of converting 


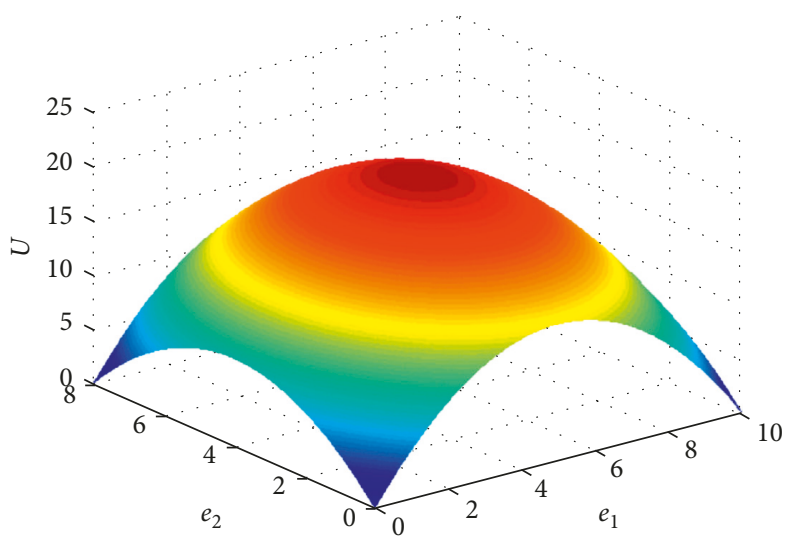

(a)

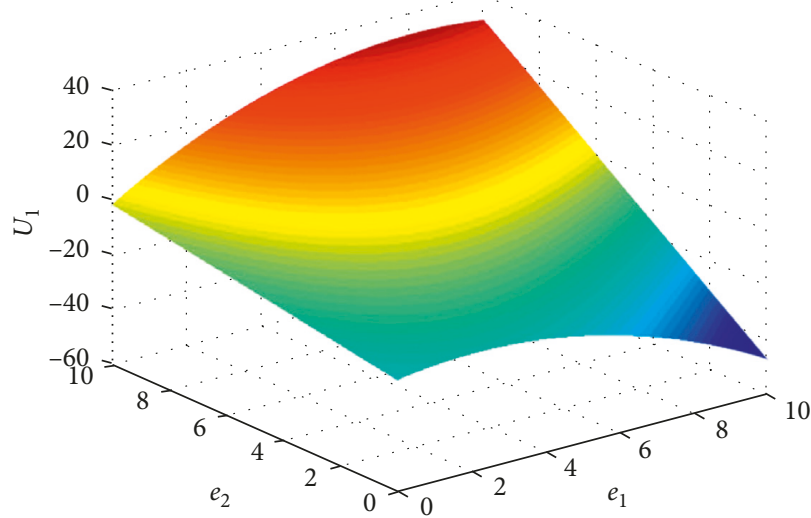

(b)

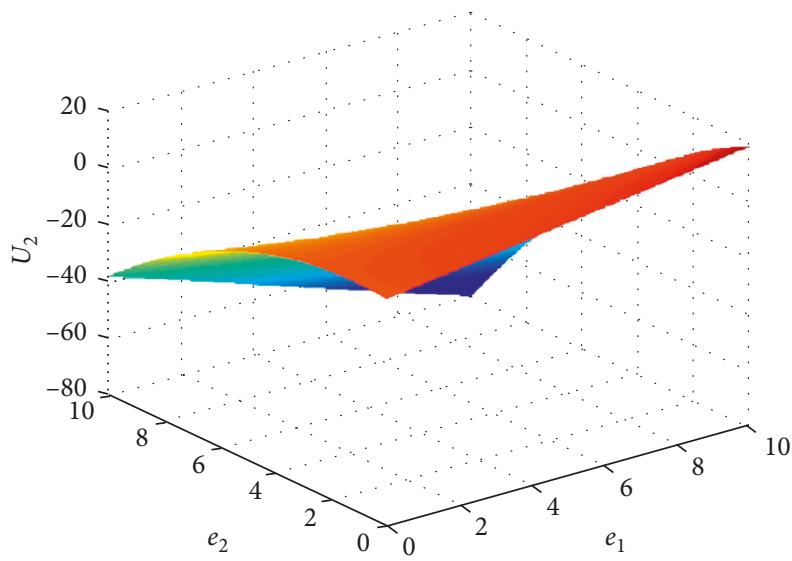

(c)

FIGURE 2: Effects of effort levels of the owner and contractor on project benefits. (a) Effects of $e_{1}$ and $e_{2}$ on $U$. (b) Effects of $e_{1}$ and $e_{2}$ on $U_{1}$. (c) Effects of $e_{1}$ and $e_{2}$ on $U_{2}$.

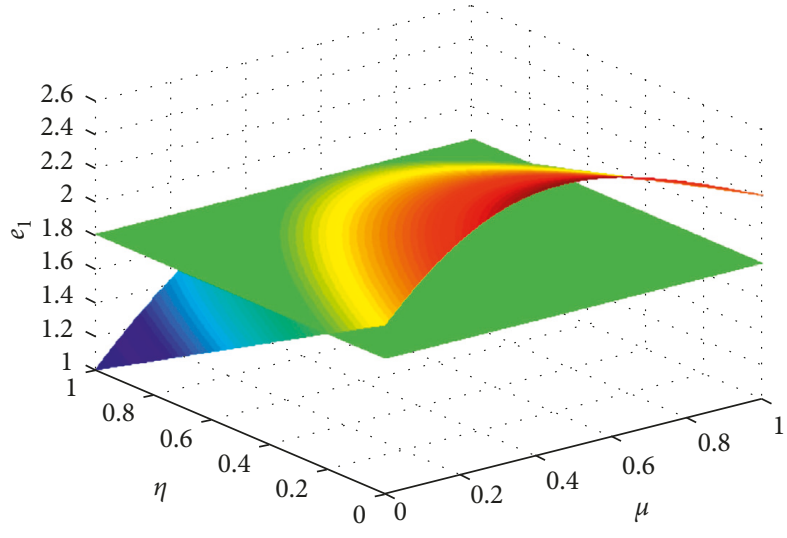

(a)

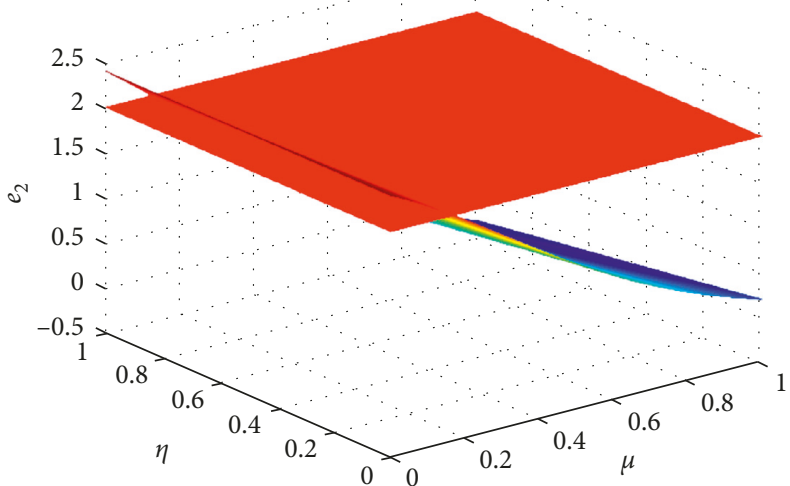

(b)

FiguRE 3: Effects of coefficients of converting conflicts to benefit and the loss caused by conflicts on effort levels. (a) Effects of $\mu$ and $\eta$ on $e_{1}$. (b) Effects of $\mu$ and $\eta$ on $e_{2}$.

conflicts to benefits $(\mu)$ and the loss caused by conflicts $(\eta)$ on effort levels $\left(e_{1}, e_{2}\right)$, under conflicting and nonconflicting conditions. Figure 3 shows the results, demonstrating that when there are conflict behaviors between the contractor and owner, higher levels of the coefficient of converting conflicts to benefit $(\mu)$ and lower levels of the coefficient of the loss caused by conflicts $(\eta)$ contribute to higher levels of effort by the contractor. Lower levels of the coefficient of converting conflicts to benefits $(\mu)$ and higher levels of the coefficient of the loss caused by conflicts $(\eta)$ contribute to 


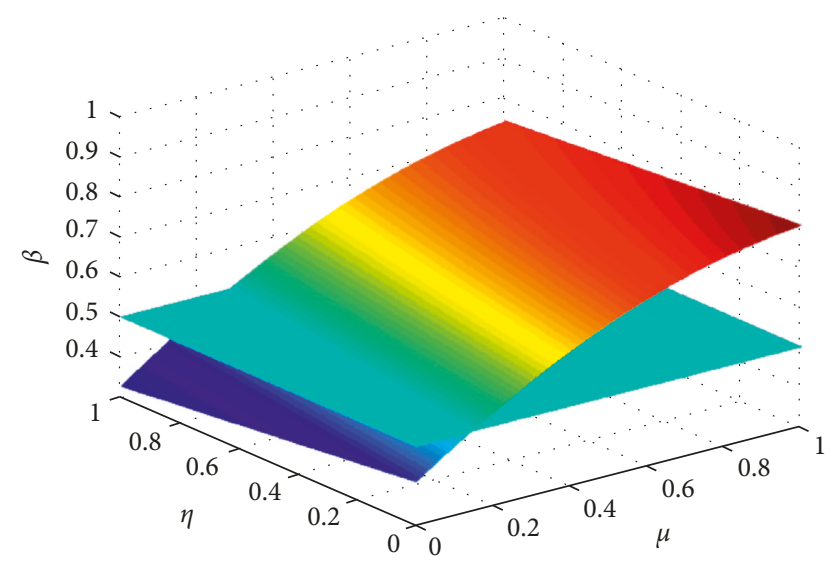

FIGURE 4: Effects of coefficients of converting conflicts to benefit and the loss caused by conflicts on the coefficient of benefit allocation.

higher levels of effort of the owner. This is consistent with Proposition 3. Compared with Figures 3(a) and 3(b), the effort levels of the contractor and owner under conflicting conditions may exceed their corresponding values under nonconflicting condition. This reflects the fact that if conflicts can bring more benefits for the owner and contractor, both may be willing to initiate conflict behaviors. This also means conflict behaviors may have a constructive effect on project benefits, which benefits the effort levels of the owner and contractor. The critical question is whether the constructive effect simultaneously affects the owner and contractor. In other words, it creates the question of whether there is a balanced point $\left(\mu^{*}, \eta^{*}\right)$ that maximizes values of $\left(e_{1}, e_{2}\right)$. In fact, this situation may be achieved when considering the effects of different types of conflicts. The contractor should consider and control the relationship between the benefit and loss caused by conflict behaviors, adjusting their influence on the owner's effort level. Furthermore, the owner should adjust its strategy to respond to contractor behaviors. Under these conditions, conflict behaviors between the owner and contractor may be constructive and contribute to project benefits. This verifies the constructive aspect of conflict behaviors in construction projects.

\subsubsection{Effects of Coefficients of Converting Conflicts to Benefit} and the Loss Caused by Conflicts on the Coefficient of Benefit Allocation. Based on (11), (13), and (14), we set $\kappa_{1}=5$, $\kappa_{2}=4$, and $\rho \sigma^{2}=20$. We then simulate the effects of the coefficient of converting conflicts to benefit $(\mu)$, and the loss caused by conflicts $(\eta)$ on the coefficient of benefit allocation $(\beta)$, under conflicting and nonconflicting conditions. Figure 4 shows the results, demonstrating that conflict behaviors between the contractor and owner lead to higher levels of the coefficient of converting conflicts to benefit $(\mu)$ and lower levels of the coefficient of the loss caused by conflicts $(\eta)$ contribute to a greater allocation of benefits to the contractor. This is consistent with Proposition 4. Compared with the nonconflicting condition, the coefficient of benefit allocation $(\beta)$ may be higher or lower than the corresponding value with the variation of coefficients of converting conflicts to the benefit and loss caused by conflicts. This reflects the fact that triggering conflict behaviors would not always benefit the contractor; in fact, it may cause a loss for the contractor. Therefore, the contractor should balance coefficients of converting conflicts to benefit and the loss caused by conflicts and consider the owner's scoping strategy. This would lead the contractor to reasonably select its own behaviors and effort level, with a goal of increasing its own net benefit.

4.2.4. Effects of Coefficients of Converting Conflicts to Benefit and the Loss Caused by Conflicts on Project Benefits. Based on (3)-(8), we set $\kappa_{1}=5, \kappa_{2}=4, \rho \sigma^{2}=20, \mu=0.6$, and $\eta=0.3$. Then, we simulate the effects of the coefficients of converting conflicts to benefits $(\mu)$ and the loss caused by conflicts $(\eta)$ on the project benefit $(U)$, the contractor's net benefit $\left(U_{1}\right)$, and the owner's net benefit $\left(U_{2}\right)$ under conflicting and nonconflicting conditions. Figure 5 shows the results and demonstrates that lower levels of the coefficient of converting conflicts to benefit $(\mu)$ and lower levels of the coefficient of the loss caused by conflicts $(\eta)$ contribute to greater project benefits. Higher levels of the coefficient of converting conflicts to benefit $(\mu)$ and lower levels of the coefficient of the loss caused by conflicts $(\eta)$ contribute to greater net benefits for the contractor. Lower levels of the coefficient of converting conflicts to benefit $(\mu)$ and higher levels of the coefficient of the loss caused by conflicts $(\eta)$ contribute to greater net benefits for the owner. Compared with Figures 5(b) and 5(c), the net benefit of the contractor is reflected in an inverted $U$ shape, with the variation of the coefficient of converting conflicts to benefit $(\mu)$, the owner's net benefit is represented by an inverted $U$ shape with the variation of the coefficient of the loss caused by conflicts $(\eta)$. This indicates that if the owner can design a reasonable conflict management mechanism, the contractor can balance the relationship between the benefit and loss caused by conflict behaviors. Under this situation, the destructive effect of conflicts can be avoided, and the constructive effect of conflicts can be introduced. Additionally, compared with Figures 5(a)-5(c), conflict behaviors between the owner and contractor appear to have constructive effects on project benefits, thus strengthening the net benefits for the owner and contractor.

4.2.5. Numerical Example. In this section, different situations of outcome coefficients of the owner and contractor are addressed to compare the model results. In addition, different situations of the coefficients of converting conflicts to benefit $(\mu)$ and the loss caused by conflicts $(\eta)$ under the same outcome coefficients of the owner and contractor are calculated. Applying the conflict decision model with owner and contractor parameter values allows the calculation of effort levels of the owner and contractor, the net benefits for the owner and contractor, the benefit allocation coefficient, 


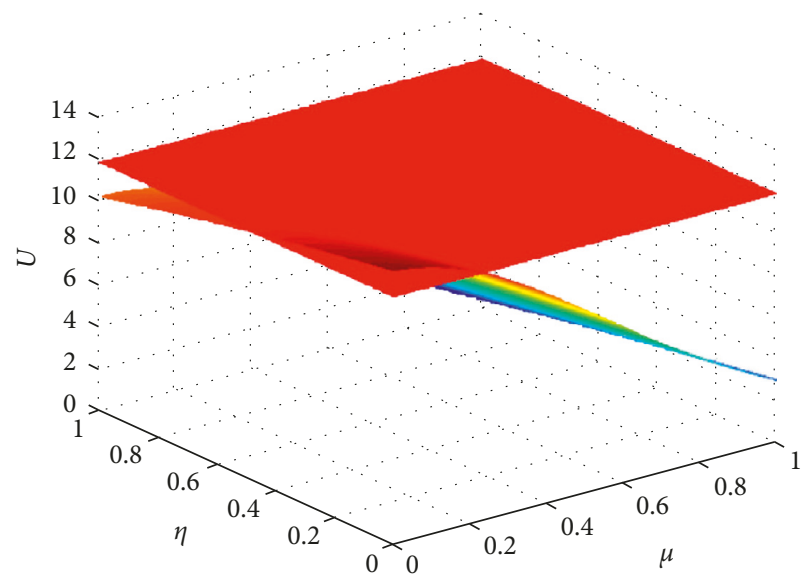

(a)

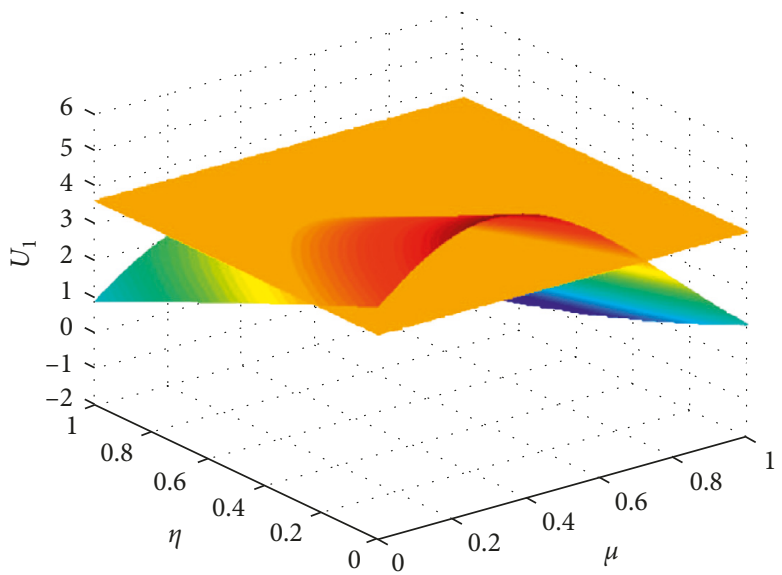

(b)

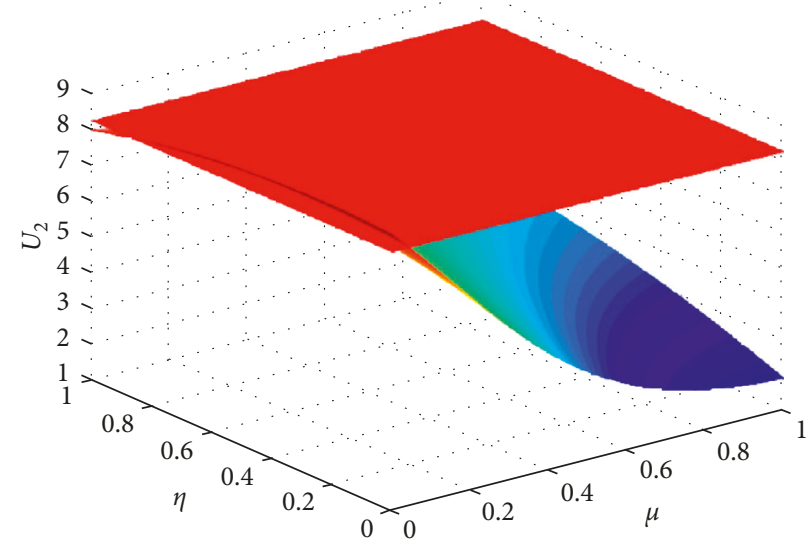

(c)

Figure 5: Effects of coefficients of converting conflicts to benefit and the loss caused by conflicts on benefits. (a) Effects of $\mu$ and $\eta$ on $U$. (b) Effects of $\mu$ and $\eta$ on $U_{1}$. (c) Effects of $\mu$ and $\eta$ on $U_{2}$.

TABLE 1: The results of conflict decision model between the owner and contractor under different situations.

\begin{tabular}{|c|c|c|c|c|c|c|}
\hline & & $\left(e_{1}, e_{2}\right)$ & $\beta$ & $U_{1}$ & $U_{2}$ & $U$ \\
\hline \multirow{6}{*}{$\kappa_{1}=5, \kappa_{2}=4$} & $\mu=0, \eta=0$ & $(2.05,2.36)$ & 0.41 & 4.29 & 8.83 & 13.12 \\
\hline & $\mu=0.1, \quad \eta=0.9$ & $(1.69,1.91)$ & 0.48 & 2.80 & 7.75 & 10.55 \\
\hline & $\mu=0.3, \quad \eta=0.3$ & $(3.21,0.30)$ & 0.68 & 6.08 & 1.29 & 7.37 \\
\hline & $\mu=0.3, \eta=0.6$ & $(2.83,0.53)$ & 0.66 & 1.11 & 6.73 & 7.84 \\
\hline & $\mu=0.6, \quad \eta=0.3$ & $(3.20,-1.40)$ & 0.86 & 4.03 & -7.31 & -3.28 \\
\hline & $\mu=0.9, \quad \eta=0.1$ & $(3.72,-2.54)$ & 0.96 & 3.19 & -17.19 & -14.00 \\
\hline \multirow{6}{*}{$\kappa_{1}=4, \kappa_{2}=4$} & $\mu=0, \eta=0$ & $(1.23,2.77)$ & 0.31 & 3.22 & 7.24 & 10.46 \\
\hline & $\mu=0.1, \quad \eta=0.9$ & $(0.83,2.44)$ & 0.37 & 2.57 & 5.79 & 8.36 \\
\hline & $\mu=0.3, \quad \eta=0.3$ & $(2.29,1.04)$ & 0.57 & 1.74 & 5.17 & 6.91 \\
\hline & $\mu=0.3, \eta=0.6$ & $(1.94,1.25)$ & 0.54 & 1.67 & 5.51 & 7.18 \\
\hline & $\mu=0.6, \quad \eta=0.3$ & $(2.13,0.44)$ & 0.74 & 3.93 & 3.28 & 7.21 \\
\hline & $\mu=0.9, \quad \eta=0.1$ & $(2.42,-1.47)$ & 0.89 & 1.76 & 0.25 & 2.01 \\
\hline \multirow{6}{*}{$\kappa_{1}=4, \kappa_{2}=5$} & $\mu=0, \quad \eta=0$ & $(1.05,3.69)$ & 0.27 & 4.70 & 9.90 & 14.60 \\
\hline & $\mu=0.1, \quad \eta=0.9$ & $(0.71,3.32)$ & 0.32 & 4.56 & 8.11 & 12.67 \\
\hline & $\mu=0.3, \quad \eta=0.3$ & $(2.28,1.73)$ & 0.52 & 4.42 & 6.61 & 11.03 \\
\hline & $\mu=0.3, \eta=0.6$ & $(1.96,1.95)$ & 0.49 & 4.28 & 7.04 & 11.32 \\
\hline & $\mu=0.6, \quad \eta=0.3$ & $(2.51,1.34)$ & 0.71 & 6.65 & 2.12 & 8.77 \\
\hline & $\mu=0.9, \quad \eta=0.1$ & $(2.89,0.58)$ & 0.80 & 2.06 & 1.22 & 3.28 \\
\hline
\end{tabular}


and the project benefits under different situations. Table 1 shows the results.

\section{Conclusions and Implications}

This study considered the effects of conflict behaviors on project benefits. Based on the inherent nature of construction projects, this study constructed a decision model between the owner and contractor's conflict behaviors, then analyzed the model under conflicting and nonconflicting conditions. A simulation and numerical example were implemented to verify the conclusions from the model analysis. The study led to four key results. First, effort levels for the contractor and owner only relate to coefficients of benefit sharing and effort outcomes under nonconflicting condition. Effort levels also relate to the coefficients for converting conflicts to benefits and the loss caused by conflicts under conflicting condition. Second, higher levels of the coefficients for converting conflicts to benefits and lower levels of the coefficient of the loss caused by conflicts contribute to a higher level of net benefits for the contractor and a lower level of net benefits for the owner. Third, this study verified the constructive effect of conflict behaviors between the owner and contractor; conflict behaviors may have constructive effects on the project benefits. This can strengthen the net benefits for the owner and contractor. Fourth, if the owner can design a reasonable conflict management mechanism, the contractor can balance and control the benefit and loss caused by conflicts. This has the benefit of strengthening the effort levels for the owner and contractor, improving project benefits.

Due to complementary core abilities and consistency in the willingness to cooperate, conflict behaviors between the owner and contractor in construction projects are cooperative-based conflicts. As such, conflicts may have constructive effects on project benefits. The conclusions of this study highlight three key implications for project management. First, the coefficient of benefit allocation depends on two factors: contractor-related factors, such as the coefficient of effort outcome, converting conflicts to benefits; and project-related factors, such as the project's external uncertainty. Facing a complex external project environment makes it difficult for the owner to evaluate the effort level of the contractor; as such, the owner may adopt a weak incentive intensity. Second, balancing the benefit and loss caused by conflict behaviors can lead to a more reasonable risk allocation between the owner and contractor [35]. This can prompt the owner and contractor to enhance their own effort levels, achieving improvements in benefits. Third, the owner should construct a fair and reasonable benefit-sharing mechanism and optimize the level of resource input and allocation between the owner and contractor. This builds a trust relationship between the owner and contractor, thus avoiding the destructive effects of conflicts and promoting constructive effects.

Few studies have emphasized effects of conflict on construction project benefits. This study constructed a decision model using game theory to bridge this gap. This study contributes significant theoretical and practical insights to manage conflicts in construction projects. However, an evaluation of the proposed model and conclusions must also consider the study's limitations. First, the proposed model considers the interorganizational relationship between the owner and contractor, while the conflict relationship may involve more stakeholders. Second, this study did not address different types of conflicts that may also affect benefits. In project practice, contractor's commitment may change as the project life cycle evolves, and the influence of conflicts on project benefits may change. These limitations highlight future research directions. In conclusion, this study contributes to the existing knowledge by proposing and validating a game-based decision model that project managers can use to address conflicts in construction projects. The model highlights practical implications, providing a clear understanding of effects of conflict on benefits in construction projects. The study also provides a theoretical reference for properly managing conflicts among stakeholders and realizing overall project benefits.

\section{Data Availability}

The data of this research is available on the request to the corresponding author.

\section{Conflicts of Interest}

The authors declare no conflicts of interest.

\section{Acknowledgments}

This study is supported by the National Natural Science Foundation of China (71561009, 71310165, and 71774023), China Postdoctoral Science Foundation (2016M590605 and 2017T100477), Postdoctoral Science Foundation of Jiangxi Province (2016KY27), Social Science Planning Foundation of Jiangxi Province (16GL32), and Natural Science Foundation of Jiangxi Province (20171BAA218004).

\section{References}

[1] B. G. Hwang, X. Zhao, and K. J. Goh, "Investigating the clientrelated rework in building projects: the case of Singapore," International Journal of Project Management, vol. 32, no. 4, pp. 698-708, 2014.

[2] J. Ding, "Investigation and analysis of inter-organizational conflict for construction projects in China," Construction Economy, vol. 21, no. 2, pp. 16-19, 2012.

[3] Y. Chen, Y. Zhang, and S. Zhang, "Impacts of different types of owner-contractor conflict on cost performance in construction projects," Journal of Construction Engineering and Management, vol. 140, no. 6, p. 04014017, 2014.

[4] W. Jiang, Y. Lu, and Y. Le, "Trust and project success: a twofold perspective between owners and contractors," Journal of Management in Engineering, vol. 32, no. 6, p. 04016022, 2016.

[5] Z. Zhao, Y. Wu, and H. Wang, "The current situation of construction project management in China," Construction Economy, vol. 14, no. 3, pp. 59-63, 2005.

[6] L. Zhu, X. Zhao, and D. K. H. Chua, “Agent-based debt terms' bargaining model to improve negotiation inefficiency in PPP 
projects," Journal of Computing in Civil Engineering, vol. 30, no. 6, p. 4016014, 2016.

[7] X. Zhao, B. G. Hwang, and Y. Gao, "A fuzzy synthetic evaluation approach for risk assessment: a case of Singapore's green projects," Journal of Cleaner Production, vol. 115, pp. 203-213, 2016.

[8] X. Zhao, B. G. Hwang, and W. Phng, "Construction project risk management in Singapore: Resources, effectiveness, impact, and understanding," KSCE Journal of Civil Engineering, vol. 18, no. 1, pp. 27-36, 2014.

[9] K. A. Jehn and C. Bendersky, "Intragroup conflict in organizations: a contingency perspective on the conflict-outcome relationship," Research in Organizational Behavior, vol. 25, pp. 187-242, 2003.

[10] C. Mele, "Conflict and value co-creation in project networks," Industrial Marketing Management, vol. 40, no. 8, pp. 13771385, 2011.

[11] G. Wu, X. Zhao, and J. Zuo, "Effects of inter-organizational conflicts on construction project added valued in China," International Journal of Conflict Management, vol. 28, no. 5, pp. 695-723, 2017.

[12] G. Wu, C. Liu, X. Zhao, and J. Zuo, "Investigating the relationship between communication-conflict interaction and project success among construction project teams," International Journal of Project Management, vol. 35, no. 8, pp. 1466-1482, 2017.

[13] N. Panteli and S. Sockalingam, "Trust and conflict within virtual inter-organizational alliances: a framework for facilitating knowledge sharing," Decision Support Systems, vol. 39, no. 4, pp. 599-617, 2005.

[14] D. K. H. Chua and Y. Song, "Application of component state model for identifying constructability conflicts in a merged construction schedule," Advances in Engineering Software, vol. 34, no. 11-12, pp. 671-681, 2003.

[15] X. Xue, Y. Wang, Q. Shen, and X. Yu, "Coordination mechanisms for construction supply chain management in the Internet environment," International Journal of Project Management, vol. 25, no. 2, pp. 150-157, 2007.

[16] R. L. Pinkley, J. Brittain, and M. A. Neale, "Managerial thirdparty dispute intervention: An inductive analysis of intervenor strategy selection," Journal of Applied Psychology, vol. 80, no. 3, pp. 386-402, 1995.

[17] X. Xue, Q. Shen, and Z. Ren, "Critical review of collaborative working in construction projects: business environment and human behaviors," Journal of Management in Engineering, vol. 26, no. 4, pp. 196-208, 2010.

[18] T. W. Yiu and S. O. Cheung, "Behavioral transition: a framework for the construction conflict - Tension relationship," IEEE Transactions on Engineering Management, vol. 54, no. 3, pp. 498-505, 2007.

[19] M. Halac, "Relationship building: conflict and project choice over time," Journal of Law, Economics, and Organization, vol. 30, no. 4, pp. 683-708, 2014.

[20] S. O. Cheung, T. S. T. Ng, and S. P. Wong, "Behavioral aspects in construction partnering," International Journal of Project Management, vol. 21, no. 5, pp. 333-343, 2003.

[21] X. Chen and K. Zhao, "An empirical study of team conflict, conflict management and performance," Nankai Business Review, vol. 13, pp. 31-35, 2010.

[22] S. Wang, J. Bai, and Y. Le, "Scale development and evaluation on project team members conflict management model," East China Economic Management, vol. 28, pp. 162-168, 2014.

[23] M.-H. Chen, "Understanding the benefits and detriments of conflict on team creativity process," Creativity and Innovation Management, vol. 15, no. 1, pp. 105-116, 2006.
[24] L. L. Anderson and B. Polkinghorn, "Managing conflict in construction megaprojects: Leadership and third-party principles," Conflict Resolution Quarterly, vol. 26, no. 2, pp. 167-198, 2008

[25] J. Brockman, "Interpersonal conflict in construction: cost, cause, and consequence," Journal of Construction Engineering and Management, vol. 140, no. 2, p. 04013050, 2014.

[26] J. Puck and U. Pregernig, "The effect of task conflict and cooperation on performance of teams : are the results similar for different task types?," European Management Journal, vol. 32, no. 6, pp. 870-878, 2014.

[27] L. Chen, B. Yang, and R. Jing, "Paternalistic leadership team conflict, and TMT decision effectiveness: interactions in the Chinese context," Management and Organization Review, vol. 11, no. 4, pp. 739-762, 2015.

[28] G. Wu, "The relationship between project team dynamic feature, conflict dimension and project success," Pakistan Journal of Statistics, vol. 29, pp. 935-952, 2013.

[29] G. Wu, X. Zhao, and J. Zuo, "Relationship between project's added value and the trust-conflict interaction among project teams," Journal of Management in Engineering, vol. 33, no. 4, p. 04017011, 2017.

[30] G. Wu, X. Zhao, J. Zuo, and G. Zillante, "Effects of contractual flexibility on conflict and project success in megaprojects," International Journal of Conflict Management, vol. 29, no. 2, pp. 253-278, 2018.

[31] G. Wu, J. Zuo, and X. Zhao, "Incentive model based on cooperative relationship in sustainable construction projects," Sustainability, vol. 9, no. 12, p. 1191, 2017.

[32] W. Lu, L. Zhang, and Y. Fu, "Improving subjective value in construction claim negotiations: role of behavioral primers," Journal of Management in Engineering, vol. 32, no. 4, p. 05016005, 2016.

[33] S. B. Zhang, Y. F. Fu, Y. Gao, and X. D. Zheng, "Influence of trust and contract on dispute negotiation behavioral strategy in construction subcontracting," Journal of Management in Engineering, vol. 32, no. 4, p. 04016001, 2016.

[34] Y. Chen, Y. Fu, and D. Hua, "A multi-task incentive model between the owner and contractor," Journal of Chinese Management, vol. 19, pp. 45-54, 2016.

[35] B.-G. Hwang, X. Zhao, and G. S. Yu, "Risk identification and allocation in underground rail construction joint ventures: contractors'perspective," Journal of Civil Engineering and Management, vol. 22, no. 6, pp. 758-767, 2016. 


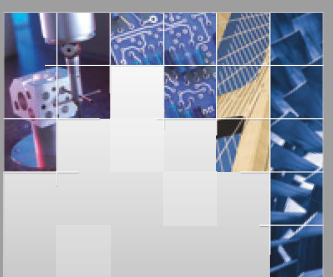

\section{Enfincering}
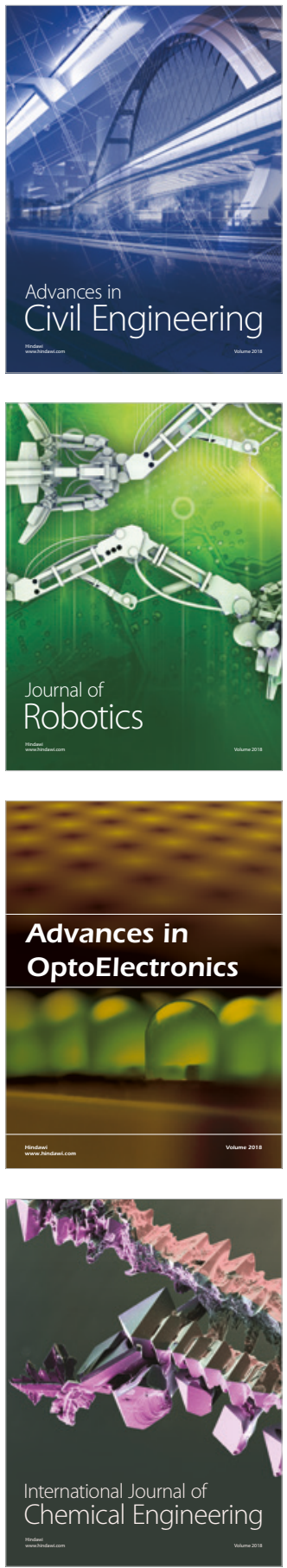

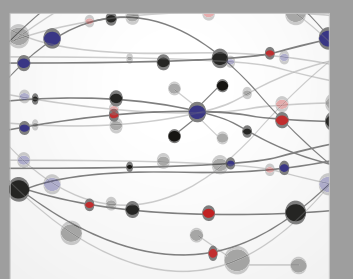

\section{Rotating \\ Machinery}

The Scientific World Journal

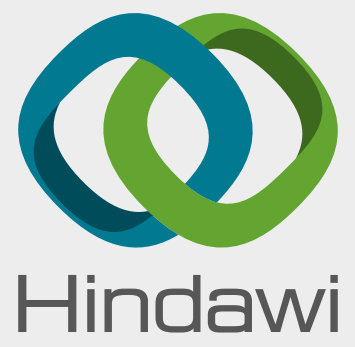

Submit your manuscripts at

www.hindawi.com
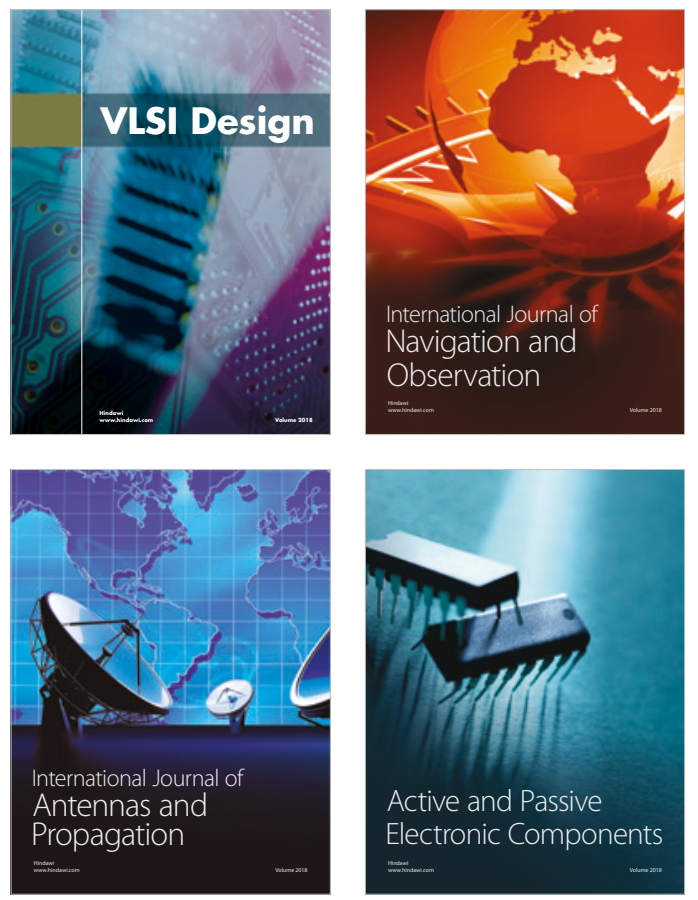
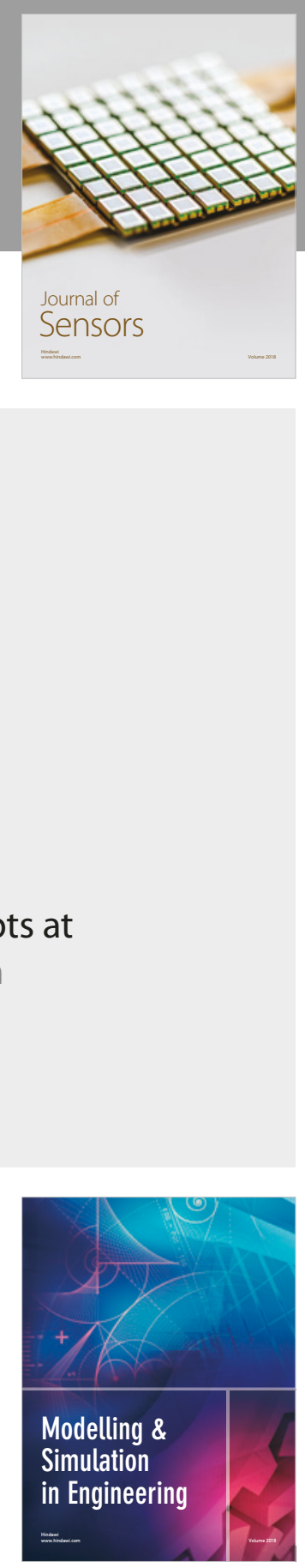

\section{Advances \\ Multimedia}
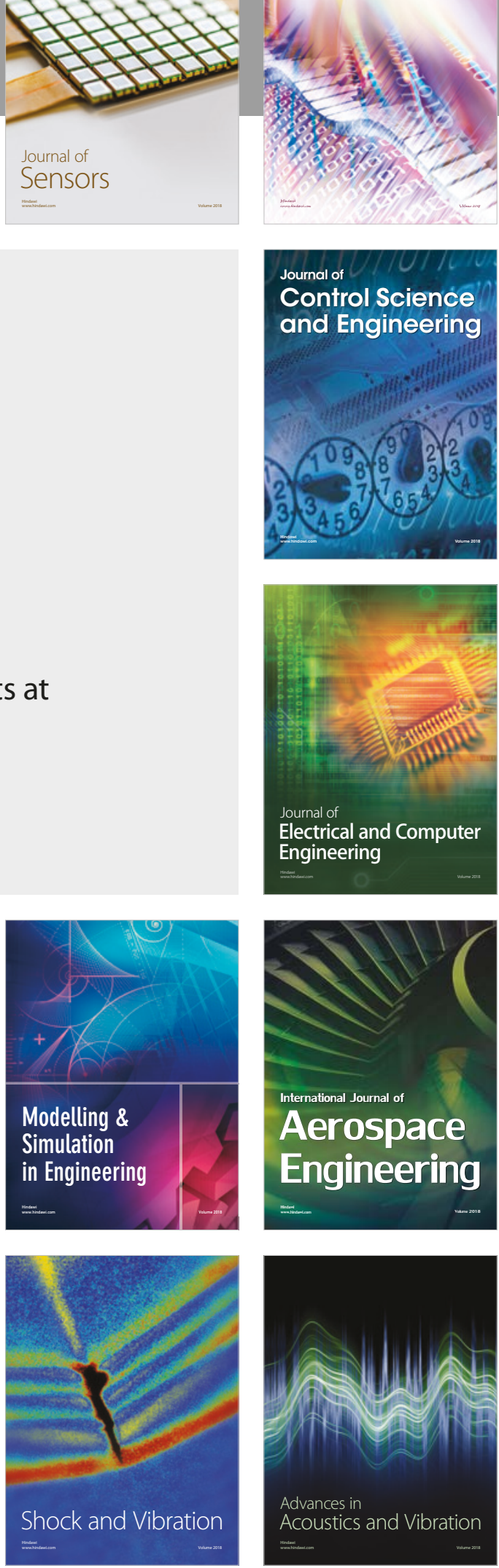